\title{
Effective Wildlife Roadkill Mitigation
}

\author{
Dion Lester \\ Pitt\&Sherry, Hobart 7000, Australia
}

\begin{abstract}
The effects of wildlife roadkill on native animal populations can be significant and the cost to people of wildlife collisions, through road crash injuries and vehicle damage, can be also significant. An understanding of roadkill causes and patterns is necessary for successful management intervention. How animals perceive, use and cross roads can vary significantly from road to road and also between different sections of the same road. This study sought to better understand the features of roadkill and successful mitigation options for a $93 \mathrm{~km}$ section of road in Tasmania's northwest. A program of baseline monitoring, analysis and trial sites informed the development of a risk based strategy for mitigating roadkill. The trial mitigation sites experienced a $50 \%$ reduction in roadkill compared with the levels prior to implementation of the trials. A number of simple, low maintenance and cost effective mitigation measures were established and offer road managers elsewhere additional options for reducing roadkill on their roads.
\end{abstract}

Key words: Roadkill, mitigation, wildlife, environmental management, roads, adaptive management.

\section{Introduction}

This article describes an adaptive management approach taken to mitigate wildlife roadkill on the proposed Tarkine Forest Drive project in northwest Tasmania. The particular focus is on the Tasmanian devil, which is critically endangered due to the impacts of DFTD (devil facial tumour disease).

The effects of roads on wildlife can be significant. Roads can disrupt wildlife populations directly through vehicles hitting animals and indirectly through forming a barrier to movement [1-3]. In Tasmania, it is estimated that there are approximately 293,000 animals killed on the roads, with an average of 1 animal killed every $3 \mathrm{~km}$ of roads [3].

There are little data available in Australia regarding the overall pattern of vehicle crashes involving animals and the cost of these crashes. While all state road authorities collect crash data, this is typically only crashes reported to the police and there is often inconsistency across jurisdiction regarding the reporting of crashes, particularly those involving

Corresponding author: Dion Lester, M.E.P., principal planner, research fields: environmental management, social impact assessment and social anthropology. E-mail: dlester@pittsh.com.au. animals [4]. In a study in 2000 of National Transport Agency data, Attewell and Glase [5] found that, from 1990-1997, there were 94 fatalities and 1,392 hospitalisations from crashes involving animals within Australia. While Rowden et al. [4] found that in Tasmania for the 2 years, 2006 and 2007, there were 11 serious causalities reported as a result of animals on the road.

The NRMA (National Roads and Motorist Association) reported that there were approximately 11,000 insurance claims in 2002 for crashes involving vehicles [4].

There is no doubt that more needs to be done to capture the true cost of vehicle crashes involving animals. An understanding of roadkill causes and patterns is also necessary for successful management intervention to reduce this cost. Because of the complexities of habitat distribution, the dynamics of wildlife populations and behaviour, and the inevitable variety of vehicles and driver motivations and experience (some careful, some not, some capable, some not), there can be no single, fixed mitigation solution. Management and mitigation measures need to adapt to the findings of ongoing monitoring that measures their effectiveness over time, with the aim of 
steady and progressive improvement, using an adaptive management approach.

Adaptive management is a systematic process for continually improving management by learning from outcomes. Adaptive environmental management recognizes the complex and interrelated character of ecosystems, with flexibility required within the process to account for any changes in conditions or the emergence of new evidence [6].

Broadly, it involves an evaluation of the issue, the development of a concept of what is occurring and what appears to be needed, followed by the implementation of initial management measures and then the monitoring of their outcomes. Importantly, the next stage involves comparing the results with the predictions and developing an understanding of what works and why, and also what does not work and why [7].

This process has merit with the unpredictable nature of environmental management, including roadkill, and has therefore formed the basis for the roadkill management plan for the Tarkine Forest Drive.
The Tarkine Forest Drive involves the upgrading of existing roads within Tasmania's northwest, with the intent to develop the tourist potential of the region by creating a self-drive experience for visitors. The route extends for $92.8 \mathrm{~km}$ from Arthur River to Tayatea Bridge (Fig. 1), and includes:

- $19.7 \mathrm{~km}$ of repairs to existing sealed road;

- $73.1 \mathrm{~km}$ of gravel pavement that requires sealing;

- two bridge replacements;

- various tourism infrastructure works;

- no new roads are proposed.

The Tarkine Forest Drive passes through a variety of environments, including some that are extremely sensitive. However, the main area of environmental concern identified during the planning and approval process was the potential for increased roadkill, particularly Tasmanian devils and spotted-tail quoll, associated with increased traffic volume and speed.

\section{Factors Influencing Roadkill}

How animals perceive, use and cross roads can vary significantly from road to road and also between

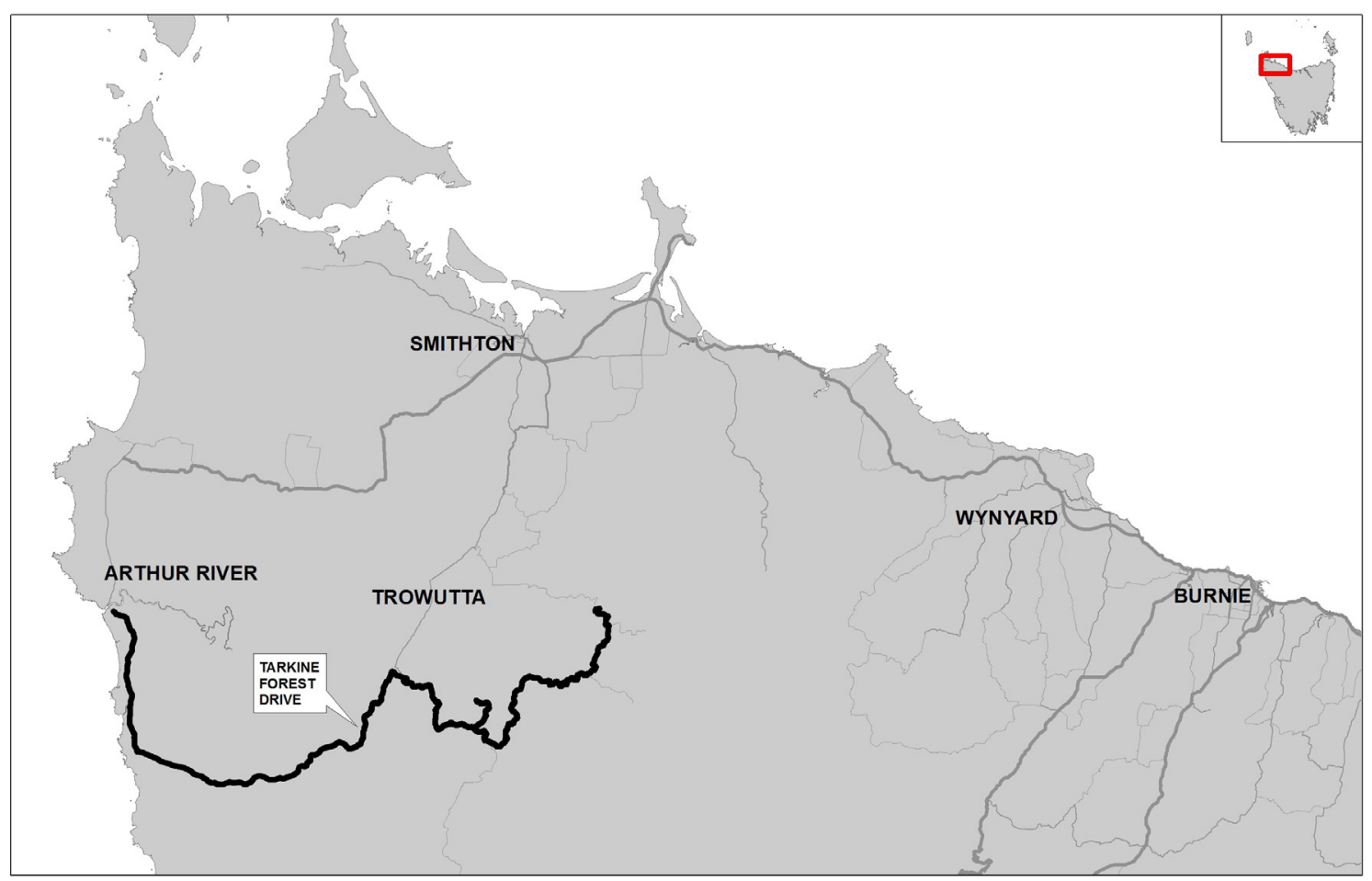

Fig. 1 Location of Tarkine Forest Drive. 
different sections of the same road [8]. Not surprisingly, there are temporal and spatial patterns to roadkill, with the majority of research indicating localised high-density roadkill areas, or "hotspots" [1, 2, 9-13].

The identification of features associated with roadkill hotspots is an important step toward implementing mitigation strategies and lessening road mortalities [11, 12, 14].

The features are generally associated with both environmental and human factors. The roadside environment, natural resources (such as standing water) and species foraging patterns are recognised as key environmental determinants $[10,12,15]$. Traffic volumes and speed, road width, visibility and roadside barriers are key human determinants of roadkill $[1,16]$. Vehicle speed and volumes are recognised as the most important human factors explaining wildlife collisions [15-17].

In Australia, the majority of species are killed at night because many are nocturnal animals and do not frequent the road during the day [1] and because visibility (for both driver and animal) is compromised at night.

\subsection{Roadkill Mitigation}

The suitability of any mitigation measure depends on local road conditions, species behaviour and ecology [14].

There are two main types of roadkill mitigation measures: changing driver behaviour and changing wildlife behaviour [10, 18].

Changing driver behaviour includes changing driver attitude by increasing public awareness, increasing awareness of roadkill hotspots and slowing speed. Ways to alter wildlife behaviour include discouraging wildlife from grazing on roadsides, preventing wildlife from crossing roads or providing safe crossings [18].

\section{A Model to Better Understand Roadkill}

To better understand roadkill rates along the
Tarkine Forest Drive, pre-construction investigations involved:

- roadkill baseline monitoring and analysis;

- a roadkill mitigation trial.

The outcomes provided a framework for developing management actions.

\subsection{Baseline Monitoring}

Roadkill surveys and the modelling of roadkill data are recognised as being important in determining the frequency of roadkill, identify hotspots and being confident of the mitigation strategy $[11,12,17]$.

A 12 month study of the abundance of both live animals and roadkill on selected roads that would make up the Tarkine Forest Drive was conducted (Fig. 2).

The following work was undertaken.

\subsubsection{Roadkill Monitoring}

The area shown in Fig. 2 of the proposed route was monitored once per week for 12 months beginning in October 2009 and also daily for $3 \times 3$ week periods during October 2009, January and April 2010.

\subsubsection{Headlight Survey}

A headlight survey was conducted daily for $3 \times 3$ week periods (63 nights) during October 2009, January and April 2010.

The aim of the headlight survey was to provide abundant data on live animals to compare with the roadkill observations.

The study area for both the roadkill monitoring and the headlight surveys encompassed the busier sections of the route, where existing impacts were likely to be measurable. There were also two reference sections where no modifications to road conditions were proposed-approximately $15 \mathrm{~km}$ along Roger River Road and $15 \mathrm{~km}$ along Sumac Road (neither of which form part of the Tarkine Forest Drive).

\subsubsection{Traffic Counts}

Traffic counts were taken in October 2009, January and April 2010, corresponding with the intensive roadkill monitoring and headlight surveys. 


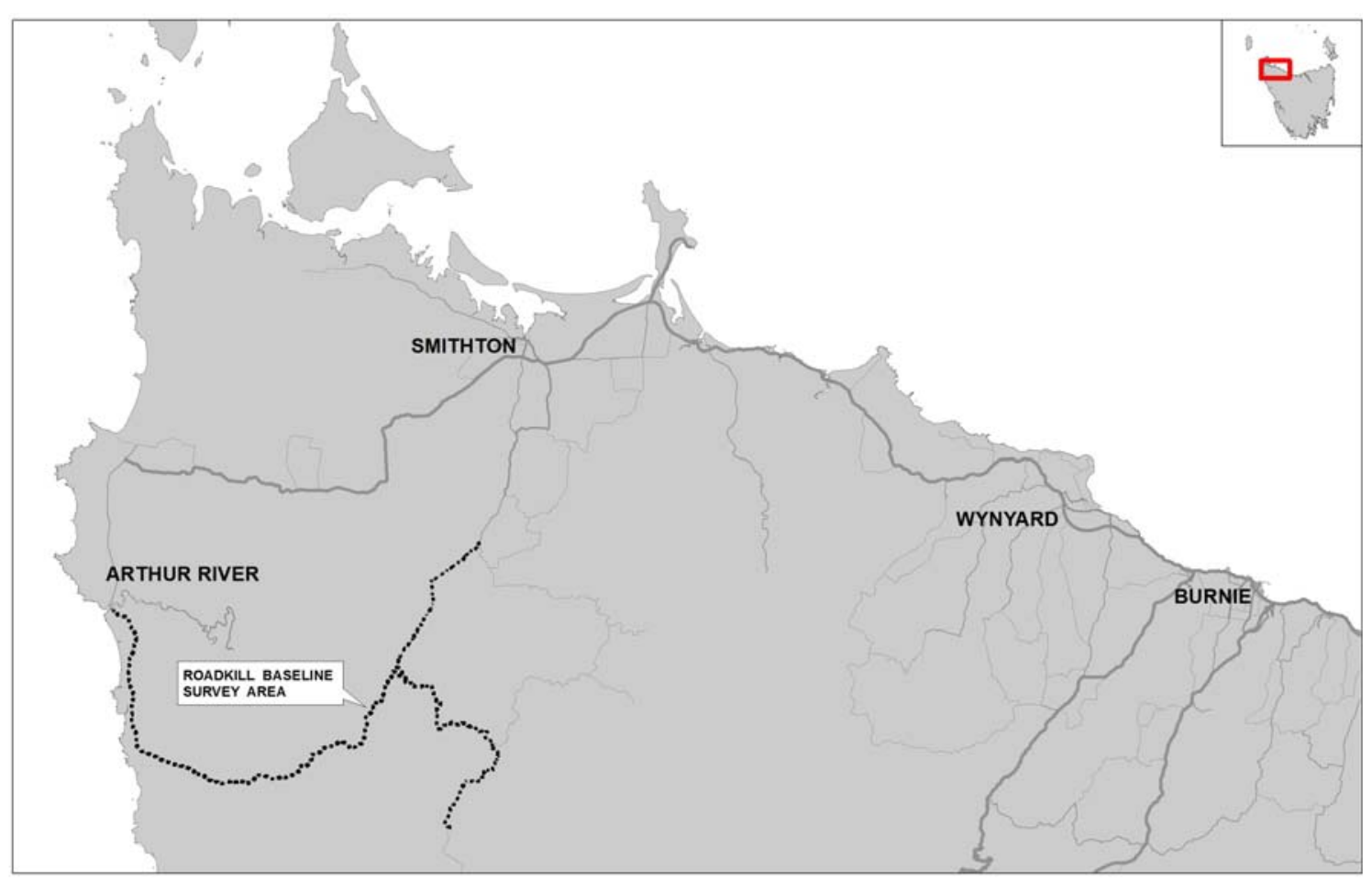

Fig. 2 Roadkill baseline survey area.

The monitoring data were subjected to statistical analysis.

The objectives of the analysis were to:

- identify spatial and other patterns in animal activity and roadkill levels;

- provide information on the baseline conditions, and to compare post construction data;

- provide insight into how the roadkill numbers will change if road traffic increases, and to inform impact assessment and adaptive management triggers;

- provide a mechanism for comparing developed and reference stretches of road for ongoing monitoring and compliance.

The key species of interest were the endangered Tasmanian devil and the vulnerable spotted-tailed quoll but patterns in activity and roadkill were analysed for all species seen.

\subsection{Monitoring Results}

\subsubsection{Headlight Survey}

There were 2,453 unique animal detections across the 63 survey nights. By far, the most common species was the Tasmanian pademelon (1,484 sightings), followed by the red-necked (aka Bennett's) wallaby (280 sightings) and the Tasmanian devil (258 sightings).

\subsubsection{Roadkill Survey}

During the survey, 188 roadkills were recorded. The species list is again dominated by the Tasmanian pademelon (141 records) and the red-necked wallaby (12 records). Five Tasmanian devils and one spotted-tailed quoll were recorded as roadkill—all on Roger River Road, one of the reference sections of the survey area.

The location and species patterns within the headlight activity and roadkill data had a strong positive correlation-where there were high animal activity levels there was increased roadkill. There was also a definite spatial clustering (or hotspots) of activity. There is a peak in roadkill $10 \mathrm{~km}$ from Arthur River, where roadkill rates are approximately six times those of some other parts of the route $(25 \mathrm{~km}$ from Arthur River). There is a secondary peak in roadkill between $35 \mathrm{~km}$ and $50 \mathrm{~km}$ from Arthur River. 
These data can be used to answer the question: if there is a road strike or headlight observation on this stretch of road, where is it most likely to occur?

\subsection{Roadkill Mitigation Trials}

To take advantage of the survey work undertaken for the current project and with a view to developing simple cost effective mitigation measures, a roadkill mitigation trial involving rumble strips was initiated.

The trial was designed specifically to test for the impact of the mitigation measures (the treatments) on roadkill rates. In real world situations, a lack of replication and randomisation of protocols often limits the generality of the findings. This was addressed through replicating treatment sites and randomising whether a location was a control site or treatment site.

To establish a positive impact, we need to be able to establish a change in the roadkill count between before and after the application of the treatment. It must also be established that this change did not occur at a similar site where there was no treatment. Therefore, a paired before-after control impact survey was used. It requires an equal number of control sites for each impact or treatment site.

The control sites had similar characteristics to the treatment sections.

The roadkill hotspots identified, during the analysis of the baseline, were used to inform the placement of on-ground roadkill mitigation trials.

Three paired trial and control sites were selected (Fig. 3): two along Roger River Road and the third on Blackwater Road. All sites were located on uniformly dark, sealed roads.

At the three trial sites, the following mitigation works were implemented:

- signage to alert drivers that they were entering a wildlife zone, including advisory signs to reduce dusk to dawn speed;

- installation of audible rumble strips-while there is little research available on their effectiveness, it was anticipated that the noise from them would provide a warning to wildlife on or adjacent to the road. This would provide a greater opportunity for animals to avoid collision. The strips would also alert drivers that

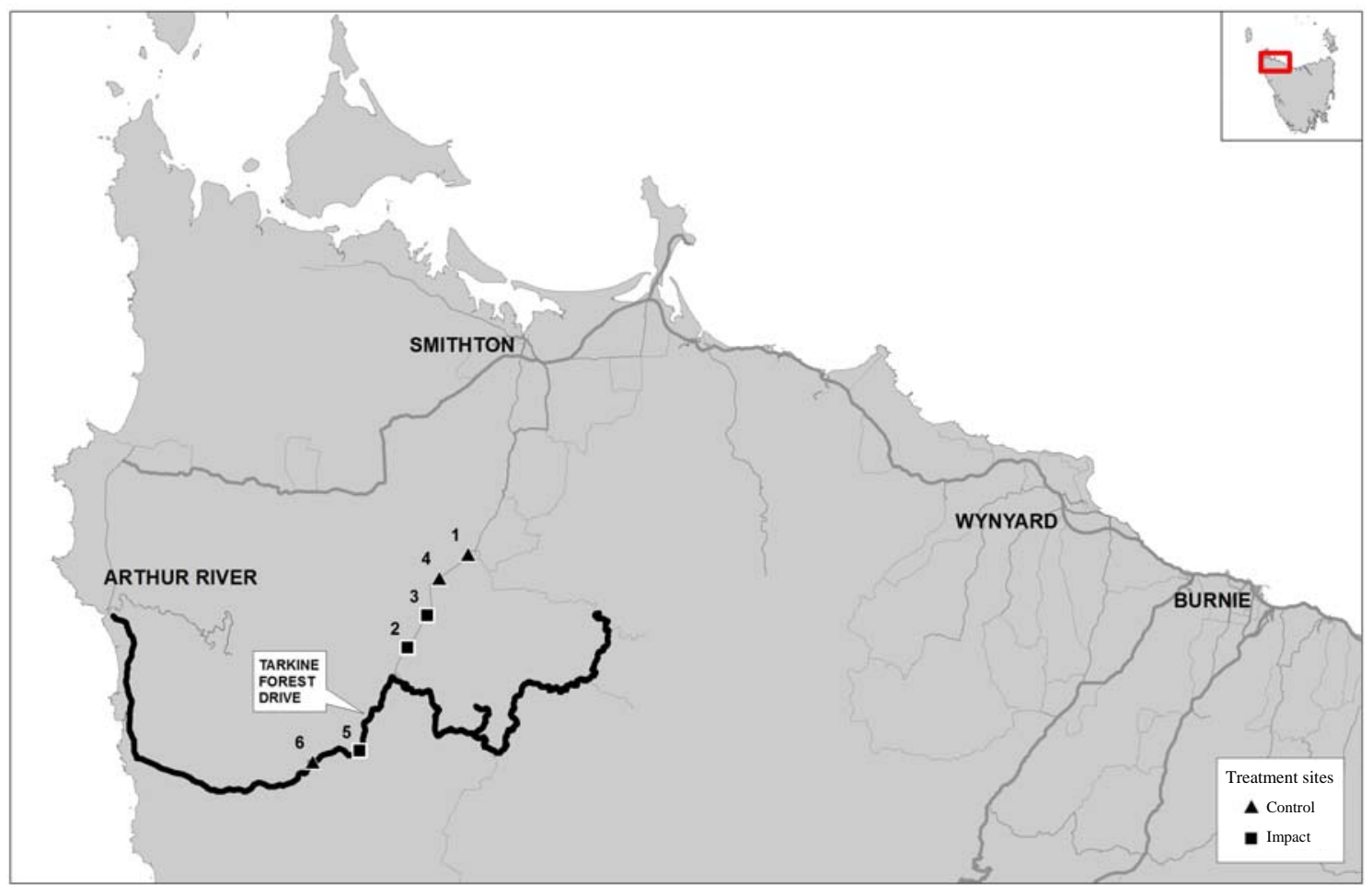

Fig. 3 Roadkill mitigation trial site. 
they were entering a special zone, and accompanying wildlife signage would encourage drivers to reduce speed and/or be more alert. The rumble strips were spaced as is shown in Fig. 4 and were $10 \mathrm{~mm}$ high thermoplastic;

- roadside and table drain clearance to reduce animal foraging, shelter and improve visibility and to discourage wildlife lingering on the roadside.

At the three control sites, no physical works were implemented.

The three paired control and treatment sites were monitored daily for roadkill for a period of 8 weeks during February and March 2012.

\section{Results}

All treated sites saw an absolute decline in numbers after the treatment, and the control sites witnessed an increase, a steady hold, and a decrease (Table 1).

The analysis concluded at a $99 \%$ confidence level $^{1}$ that the treatment sites experienced an average 59\% reduction in roadkill relative to the controls.

This gave the project team confidence to apply this form of mitigation in appropriate locations across the route, although it was not the only form of mitigation used.

\section{Roadkill Minimisation Plan}

Successful management intervention is only likely to succeed when there is an appropriate level of understanding and awareness of roadkill patterns and causes.

The factors contributing to vehicle-wildlife collisions are:

- vehicle speed, volume and time of day/year travelled;

\footnotetext{
${ }^{1}$ There is a difference in meaning between the common usage of the word "confidence" and its statistical usage, which is often confusing to the layman. In statistics, the word "confidence" is a technical term used to indicate how rare an outcome has to be before the writer will accept it as significant. For example, $99 \%$ confidence in this context means that the reduction in roadkill produced by this trial is likely to happen by chance $1 \%$ of the time.
}

- driver awareness, attitude and experience;

- roadside vegetation and road width;

- adjacent habitat;

- animal abundance.

Each of these factors were assessed in detail. From the combined results of the assessments, the project team were able to categorise the Tarkine Forest Drive

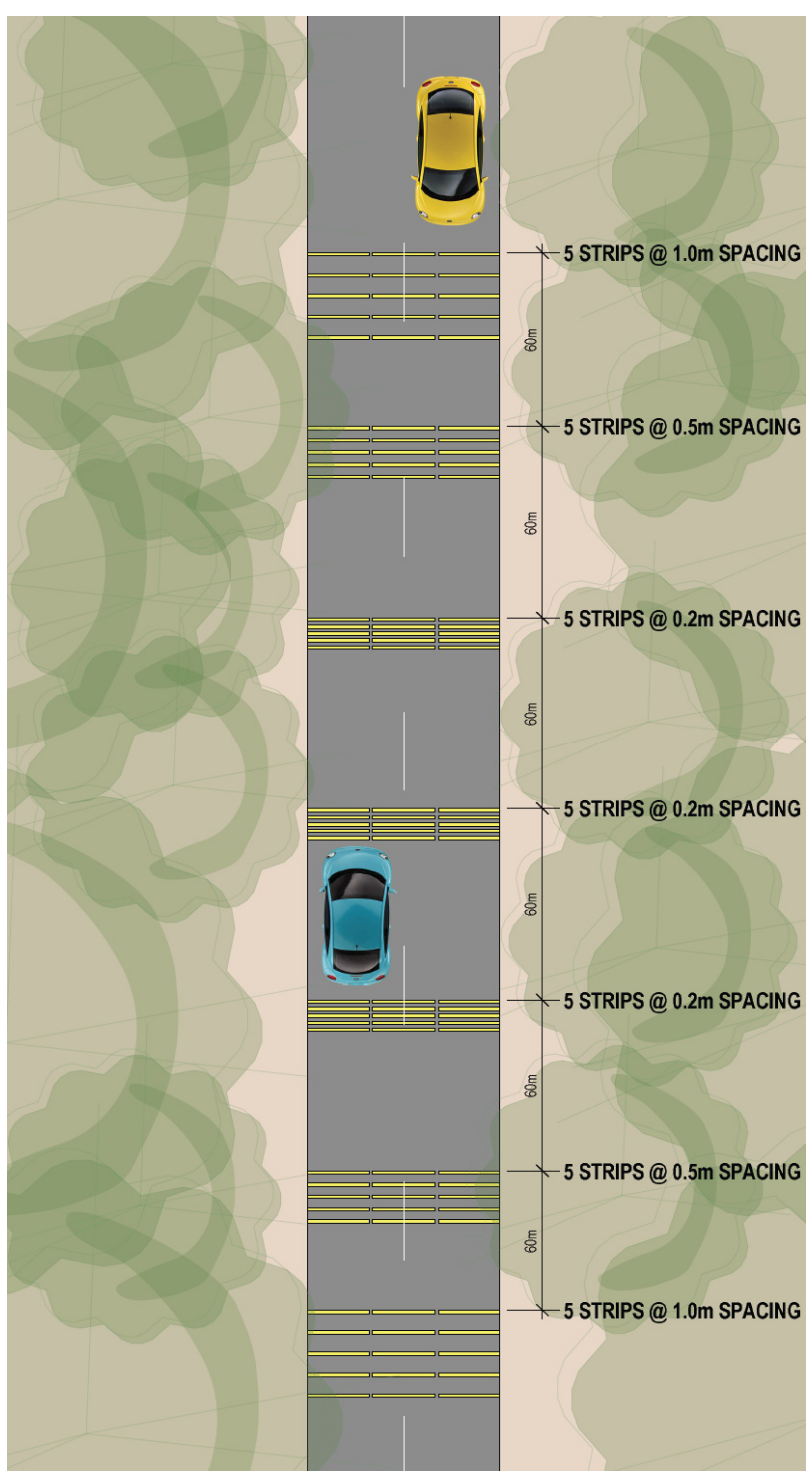

Fig. 4 Rumble strip layout.

Table 1 Summary of results.

\begin{tabular}{lllllllll}
\hline & \multicolumn{3}{c}{ Treated sites } & & \multicolumn{3}{c}{ Control sites } \\
\cline { 2 - 4 } \cline { 6 - 8 } & Two & Three & Five & & One & Four & Six \\
\hline Before & 30 & 27 & 4 & & 24 & 6 & 3 \\
After & 8 & 21 & 0 & & 34 & 6 & 0 \\
Change & & & & & & & & \\
\hline
\end{tabular}


into different roadkill risk zones. These zones were then used to inform the mitigation measures imposed. The following measures will be implemented:

- vegetation clearance and table drain design;

- rumble strips;

- light coloured pavement;

- road alignment amendments to improve visibility;

- signage;

- a community awareness program.

Each of these is briefly discussed below.

\subsection{Vegetation Clearance and Table Drain Design}

A common cross section and table drain design were implemented to counter the roadkill risks associated with areas of narrow road or where vegetation is very close to the pavement. Pavement material will be extended across the base of the table drains to ensure limited opportunity for vegetation re-growth.

The construction of better table drains along the route, which at present typically either do not exist or are very poorly formed, will aid in the transport of water and reduce water pooling directly adjacent to the road. This will reduce the likelihood of vegetation growth and of drinking water attracting animals to the roadside.

\subsection{Rumble Strips}

The success of the rumble strips trials (described above) gave the project team confidence in using this method of mitigation in appropriate locations across the route.

\subsection{Light Coloured Pavement}

It is well established that the visibility of wildlife to drivers is restricted at night. This is due to limited headlight range and because many native species are dark in colour and have poor contrast against road surfaces that themselves typically are dark $[15,16,18]$.

Light coloured pavement may decrease roadkill due to increased visibility because most animals will be more visible on a lighter surface than on a dark surface. This mitigation may be helped by most Tasmanian wildlife being dark in colour, meaning that animals may feel uncomfortable spending extended time on a light coloured road surface due to their increased exposure [14, 16, 18]. Light coloured pavement at hotspots would also have the benefit of alerting drivers to the fact that they are entering a high risk roadkill zone.

\subsection{Road Alignment Improvements}

Throughout the detailed survey and assessment phase, it became apparent that deficiencies in road alignment were causing blind spots for drivers (and animals) at a number of the hotspots. Through relatively simple improvements to a road's vertical alignment and increasing sight line distances, these blind spots could be removed. This should result in a greater opportunity for drivers and animals on the road to see each other sooner and potentially avoid collision.

\subsection{Signage}

The following roadkill specific signage is proposed:

- installation of interpretative signage at the start and end points of the route;

- wildlife advisory signs at key locations, including the roadkill hot spots which will advise of a $45 \mathrm{~km} / \mathrm{h}$ dusk-to-dawn speed limit.

\subsection{Community Awareness Program}

The following actions are proposed to raise community awareness:

- media articles in local newspapers;

- information pamphlets distributed to all property owners in and around Arthur River (a township at one end of the Tarkine Forest Drive);

- targeted pamphlets distributed to other key stakeholders, such as 4WD (four wheel drive) and camping clubs. 


\subsection{Monitoring Plan}

The adaptive management (Fig. 5) proposed for the Tarkine Forest Drive is not a random trial and error process but involves systematically monitoring outcomes to test assumptions. By monitoring before and after changes, we are able to learn how the natural system responds to those changes, so that the process can be fine-tuned through future interventions.

Following the completion of the Tarkine Forest Drive, an ongoing strategy to assess and address any increase in roadkill as a result of the project is proposed. This strategy will use an adaptive management framework to monitor, evaluate and mitigate the potential impact to key species from roadkill.

Pre-construction monitoring and analysis of roadkill patterns along the proposed Tarkine Forest Drive and nearby roads provide information on baseline levels of roadkill for different road sections. This information will be used to set expected roadkill carcass detection rates both for a given section over a given time period and for individual passes. These counts will allow trigger levels for escalating investigation and management to be established.

At all stages, monitoring will be used to support management adaptations. This is a precautionary approach, where monitoring is instigated with the specific aim of supporting management.

The following diagram summarises the staged approach and triggers. The specific values and monitoring protocols are yet to be developed, but the guiding strategy for each stage is outlined below.

\subsubsection{Stage 1: Operational Monitoring}

This stage will involve instances of roadkill and the segment(s) of road on which they occur recorded at least once per week. This minimum monitoring frequency will ensure that enough data are collected to allow a regular assessment of any changes.

This information will be assessed quarterly, and compared to the range of expected counts and the baseline data. Notes collected during operational monitoring will also be assessed, as these could provide immediate insight into unusual events.

If a trigger level is exceeded and no immediate insight or course of action is apparent, then Stage 2 monitoring will be invoked.

5.7.2 Stage 2: Formal Monitoring

If a potential increase in roadkill is detected (beyond the expected range), Stage 2 will be triggered. This will be designed to deliver two outcomes:

- to confirm the level and location of the increase;

- to provide information on the nature of the increase that can directly inform mitigation.

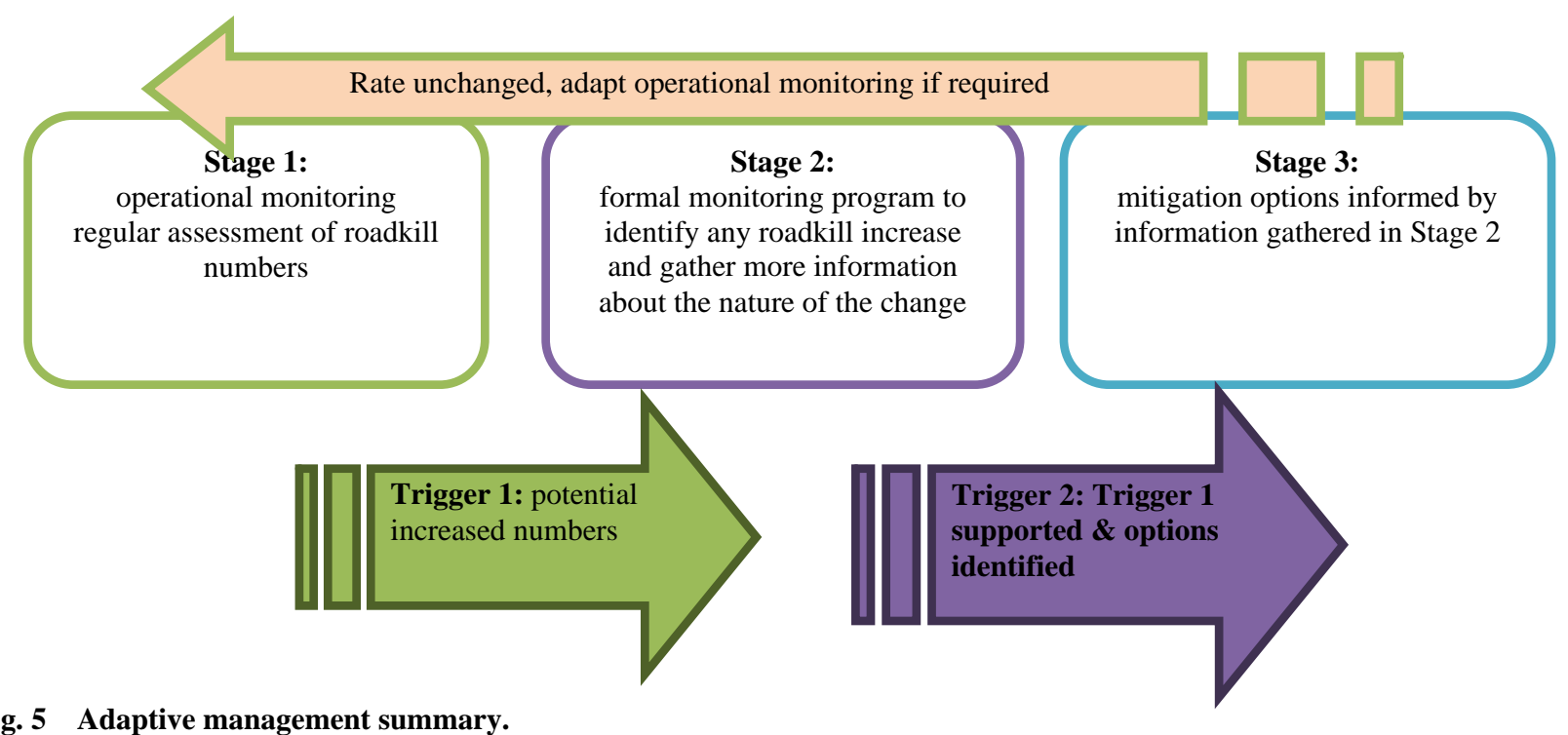

Fig. 5 Adaptive management summary. 
The second dot point is important to ensure that mitigation is effective and not poorly focussed, which could actually contribute to a detrimental impact. For example, it is important to distinguish between a flat, "global" increase that requires a global mitigation program, or a localised peak of activity, which can support a much more intense, yet localised, mitigation approach. Stage 2 seeks to focus the discussion on appropriate and effective mitigation measures, not to quantify the impact. It necessarily depends upon the nature of the concern raised in Stage 1.

\subsubsection{Stage 3: Mitigation}

To be effective, an adaptive management program must be able to identify, or suggest, where the potential impact is occurring. If this stage is reached, a significant increase in roadkill would have been detected and the nature of the increase identified. Further mitigation steps could then be developed and implemented.

The exact nature and extent of measures will depend on the information gathered in Stages 1 and 2.

Stage 3 includes a feedback cycle into the operational monitoring, to increase its efficacy based on the latest state of knowledge of the road and its environs.

\section{Conclusions}

At the time of writing, the Tarkine Forest Drive construction had not been completed, but was scheduled to latter this year. The preconstruction investigations and post construction adaptive management framework provide a useful case study for other road authorities grappling with the impacts of road upgrades (and existing roads) on wildlife.

In summary, an understanding of roadkill causes and patterns is necessary for successful management intervention. Adaptive management provides a means to gain a better understanding of a system while that system is being actively managed. This process has merit with the unpredictable nature of environmental management, including roadkill.
The steps in adaptive management are:

- define clearly what the problem is and what you are trying to achieve;

- develop a model that understands the system based on all the available information. This provides a framework for comparing management alternatives;

- from the model, develop a management plan that includes the factors you want to affect and what actions need to be done to achieve this;

- develop a monitoring plan to test assumptions, which helps to establish what is working and what is not;

- implementation of the plans (management and monitoring);

- analyse the information and communicate outcomes;

- use the results to gain a better understanding of the system. The most crucial step in the process involves returning to the original model to see if the assumptions tested turned out as predicted, and then using the results to modify the model if and as necessary.

\section{References}

[1] Hobday, A. J., and Mintrell, M. L. 2008. "Distribution and Abundance of Roadkill on Tasmanian Highways: Human Management Options." Wildlife Research 35: 712-26.

[2] Malo, J., Suarez, F., and Diez, A. 2004. "Can We Mitigate Animal-Vehicle Accidents Using Predictive Models?." Journal of Applied Ecology 41: 701-10.

[3] Roadkill Tas. 2014. "Tasmanian Roadkill Statistics." Accessed January 12, 2015. http://www.roadkilltas.com/.

[4] Rowden, P. J., Steinhardt, D. A., and Sheehan, M. C. 2008. "Road Crashes Involving Animals in Australia." Accident Analysis and Prevention 40 (6): 1865-71.

[5] Attewell, R., and Glase, K. 2000. Bull Bars and Road Trauma. Report CR200. Australian Transport Safety Bureau, Canberra.

[6] Briassoulis, H. 1989. "Theoretical Orientations in Environmental Planning: An Inquiry into Alternative Approaches." Environmental Management 13: 381-92.

[7] Salafsky, N., Margoluis, R., and Redford, K. 2001. Adaptive Management: A Tool for Conservation Practitioners. Washington: World Wildlife Fund. 
[8] Havlick, D. 2004. "Roadkill." Conservation Magazine 5 (1): 30-4.

[9] Clevenger, A., Chruszcz, B., and Gunson, K. 2003. "Spatial Patterns and Factors Influencing Small Vertebrate Fauna Road-Kill Aggregations.” Biological Conservation 109: 15-26.

[10] Coffin, A. W. 2007. "From Roadkill to Road Ecology: A Review of the Ecological Effects of Roads." Journal of Transport Geography 13: 396-406.

[11] Litvaitis, J., and Tash, J. 2008. "An Approach toward Undersatnding Wildlife-Vehicle Collision." Environmental Management 42: 688-97.

[12] Ramp, D., Caldwell, J., Edwards, K., Warton, D., and Croft, D. 2005. "Modelling of Wildlife Fatality Hotspots along the Snowy Mountain Highway in New South Wales, Australia." Biological Conservatiobn 126: 474-90.

[13] Roger, E., and Ramp, D. 2009. "Incorporating Habitat Use in Models of Fauna Fatalities on Roads." Biodiversity Research 15: 222-31.
[14] Magnus, Z. 2006. Wildlife Roadkill Mitigation Information Kit: A Guide for Local Government and Land Managers. Technical report of Sustainable Living Tasmania, Hobart, Tasmania.

[15] Hobday, A. J. 2010. "Nighttime Driver Detection Distances for Tasmanian Fauna: Informing Speed Limits to Reduce Roadkill." Wildlife Research 37: 265-72.

[16] Jones, M. 2000. "Road Upgrade, Road Mortality and Remedial Measures: Impacts on a Population of Eastern Quolls and Tasmania Devils." Wildlife Research 27: 289-96.

[17] Taylor, B., and Goldingay, R. 2010. "Roads and Wildlife: Impacts, Mitigation and Implications for Wildlife Management in Australia." Wildlife Research 37: 320-31.

[18] Magnus, Z., Kriwoken, L., Mooney, N., and Jones, M. 2004. Reducing the Incidence of Wildlife Roadkill: Improving the Visitor Experience in Tasmania. Technical report of Cooperative Research Centre for Sustainable Tourism. 